\title{
Prevalence of Osteopenia According to Physical Fitness in Men: A Cross-Sectional Study
}

\author{
Yong Hwan Kim², Dong Hyun Yoon', Hong Kyu Kim², Wook Song ${ }^{1,3}$ \\ ${ }^{1}$ Health and Exercise Science Laboratory, Institute of Sports Science, Seoul National University, Seoul, ${ }^{2}$ Health Promotion Center, Asan
} Medical Center, Seoul, ${ }^{3}$ Institute on Aging, Seoul National University, Seoul, Korea

Corresponding Author: Wook Song, $\mathrm{PhD}$

Health and Exercise Science

Laboratory, Institute of Sport

Science, Seoul National

University, 1, Gwanak-ro,

Gwanak-gu, Seoul 08826,

Korea

Tel: $+82-2-880-7791$

Fax: +82-2-872-2867

E-mail:songw3@snu.ac.kr

Received: October 7, 2017 Revised: November 30, 2017 Accepted: December 4, 2017 of osteopenia and prevent loss of BMD.

Key Words: Fitness, Bone mineral density, Osteopenia, Odds ratio

\begin{abstract}
Background: Bone mineral density (BMD) has been associated with fitness, nutrition, lifestyle, and genetic factors such as sex and race. The aim of this study was to determine whether athletic performance in middle-to-old-aged men affected the development of osteopenia. Methods: This cross-sectional study pooled data collected from 3,560 men in their 40-70's. BMD was measured by dual-energy $\mathrm{X}$-ray absorptiometry at the lumbar spine 1-4 and the femoral neck. The fitness tests included strength (grip strength), flexibility (trunk forward flexion), and cardiopulmonary fitness (maximum oxygen consumption, $\mathrm{VO}_{2 \max }$ ). Results: The participants in the normal and osteopenia groups were aged $49.9 \pm 5.0$ (mean \pm standard deviation) and $50.4 \pm 5.1$ years, respectively. Those in the highest quartile $(\mathrm{Q} 4)$ of $\mathrm{VO}_{2 \max }$ had a significantly increased risk of having osteopenia (adjusted odds ratio 1.687; 95\% confidence interval [CI] 1.193-2.387; $\mathrm{p}=0.003$ ). Participants in the highest quartile (Q4) of grip strength had a significantly higher adjusted odds ratio (1.445) of having osteopenia $(95 \% \mathrm{Cl}, 1.099-1.857 ; \mathrm{p}=0.009)$. Finally, flexibility was 1.454 times higher for the lowest group (Q4) than for the highest group (Q1) $(95 \% \mathrm{Cl}, 1.194-1.887 ; \mathrm{p}=0.003)$. Conclusion: Higher levels of cardiopulmonary fitness and flexibility in middle-aged men may decrease the prevalence
\end{abstract}

\section{INTRODUCTION}

High fitness is inversely associated with the incidence of cardiovascular disease, obesity, and all-cause mortality ${ }^{1,22}$. Among various physical fitness activities, weight training that improves muscle strength has been shown to positively affect bone mineral density $(\mathrm{BMD})^{3-6)}$. Decreased $\mathrm{BMD}$ is an important risk factor for fracture in falls. In particular, reduced BMD in frail elderly individuals is more closely related to the risk of fracture than that in healthy adults ${ }^{7}$. Fall-induced fracture is an economic burden to both society and individuals, and may also decrease patient quality of life ${ }^{8,9)}$. Physical fitness as an indicator of physical function may be a useful predictor of the risk of fall ${ }^{10}$. Traditionally, muscle strength and high-impact exercise including jumping, powerlifting, and jogging might offer protection against osteopenia and osteoporosis ${ }^{1)}$. In addition, high levels of cardiopulmonary fitness and activities of daily living are associated with lower risk of fracture and reduced $\mathrm{BMD}^{4,11,12)}$. A recent study reported that lower cardiopulmonary fitness and walking capacity were associated with decreased BMD in middle age ${ }^{13)}$. Further- more, a number of studies have recommended high-impact training such as jogging and resistance exercises to prevent this loss of $\mathrm{BMD}^{4,14,15)}$. However, people with low BMD are mainly elderly and may have joint issues such as back pain, knee arthritis, and hip pain. Therefore, it is difficult to recommend high-intensity exercise for the prevention of BMD-related diseases". However, there are few studies on this topic due to limitations in studying elderly with various diseases. For this reason, exercise programs to improve BMD in the elderly are limited. Some studies suggest that stretching and vibration training may be associated with increased bone density, but the relationship between BMD and multiple fitness remains controversial ${ }^{16,17)}$. Therefore, the aim of the present study was to analyze the prevalence of osteopenia in the elderly according to several fitness factors including endurance, strength, and flexibility.

\section{MATERIALS AND METHODS}

\section{Participants and Design}

A total of 3,560 middle-to-old-aged men in their 40-70's 
(average age, 52.6 \pm 7.4 years) participated in this cross-sectional study conducted at the Health Promotion Center of the Medical Center in Korea. Before participation, all participants were asked to complete a medical history, medication, and healthy habits (alcohol, exercise, smoking, etc.) questionnaire to screen for present and past health status. This study only included responses from participants who answered "Yes" to the question, "Do you agree that we may use your data in this study?". The exclusion criteria included those with CVs, orthopedic problems, and respiratory illnesses that posed a potential risk during the maximum fitness test. This study received approval from the Institutional Review Board of the Asan Medical Center (approval number: 20160084). Participants were asked to fast for 8 hours before testing and to not exercise except for routine activities for at least 8 hours before testing. The participants were provided with the same light gowns and pants. Participant height, weight, body composition, and blood pressure were measured and blood and urine tests were performed. After this process, the participants underwent bone density and physical fitness tests.

\section{Tests and Measurements}

\section{1) Measurement of bone mass}

The BMD $\left(\mathrm{g} / \mathrm{cm}^{2}\right)$ of the lumbar spine (L1 to L4) and femoral neck were measured by dual-energy $X$-ray absorptiometry (DEXA, GE9800, General Electric Co., Milwaukee, WI, USA). All DEXA operators were certified specialists on the basis of an evaluation of the scanning and analysis techniques. According to World Health Organization guidelines, osteopenia was defined as T-score below standard deviation (SD) -1.0 to -2.4 and participants with osteoporosis were excluded ${ }^{18)}$.

\section{2) Flexibility test}

Flexibility was assessed using the sit-and-reach method . The test was performed using a Sit \& Reach box (5003, TAKEI, Niigata, Japan) with each participant seated on the floor with knees extended, straight upper body, and arms located to the front. The participants were then directed to move forward to place their hands on the box as far forward as possible and the location of the point of maximally extended hand was measured. The assessment was performed twice, using the higher of the 2 scores.

\section{3) Hand grip strength}

The grip strength was measured using a hand grip strength dynamometer (5401, TAKEl, Niigata, Japan). The elbows were stretched and the fist was placed outside the femur in a state where the foot was in the shoulder width. The machine was adjusted to length 3 and placed in 2nd phalanges.
Measurements were made to squeeze as much as possible. Two measurements were made on both sides and high values were used.

\section{4) Maximal graded exercise test}

Each subject performed a maximal graded exercise test using a treadmill ergometer (T 150 COSMED and QUARK series by Breath Pulmonary Gas Exchange were used for functional diagnostics). The Bruce protocol was employed, which began at $1.7 \mathrm{mph}$ at a $10 \%$ grade with increasing speed and grade (i.e., $2.5 \mathrm{mph}$ at $12 \%, 3.4 \mathrm{mph}$ at $14 \%, 4.2 \mathrm{mph}$ at $16 \%, 5.0$ $\mathrm{mph}$ at $18 \%$, etc.) every 3 minutes until test termination. The test continued when the participant requested to stop or upon the development any cardiac or orthopedic condition. If the test was abnormally terminated, it was excluded from this analysis of this study.

\section{Statistical Analysis}

To study the association between the level of physical fitness and osteopenia, the participants were divided into 2 groups based on BMD. The normal group consisted of patients with BMD of -1.0 or more, while those with BMD of -1.0 to -2.4 were placed into the osteopenia group. The differences in clinical characteristics between the osteopenia and normal groups were tested for statistical significance with independent t-test and chi-square test. Logistic regression was used to analyze the odds ratios of having osteopenia for each fitness level and health habit. Factors such as age, body mass index (BMI), waist circumference, phosphorus level, testosterone level, calcium level, grip strength, and maximum oxygen consumption $\left(\mathrm{VO}_{2 \max }\right)$ were adjusted and entered in a stepwise manner in a multiple regression analysis that included habits associated with health such as exercise, smoking status, and alcohol consumption. Fitness was classified according to quartile from the highest fitness (Q1) to lower levels of fitness (O2, 3, and 4). All data are presented as means \pm SD and statistical significance was adopted for $p<0.05$. Most of the data were analyzed using IBM SPSS Statistics ver. 20.0 (IBM Co., Armonk, NY, USA).

\section{RESULTS}

\section{Participant Characteristics According to the Presence of Osteopenia}

Men with osteopenia had a lower flexibility, grip strength, and $\mathrm{VO}_{2 \max }$ than those in men with normal BMD (Table 1). Men with decreased BMD had a smaller waist circumference, lower BMI, and higher alkaline phosphate and phosphorus levels. Low-frequency exercise was inversely associated with osteopenia (Table 2). Smoking was also correlated with 
disease. The proportion of present smokers was higher in the osteopenia group than that in the normal group and the proportion of participants who had never smoked was higher in the normal than that in the osteopenia group. Finally, Table 1 shows that low bone mass was associated with age $(p<0.001)$.

\section{Odds Ratios of Osteopenia According to Health Habits}

Decreased exercise frequencies were associated with increased odds ratios of osteopenia (Table 2). These trends remained significant after adjusting for several factors and other health habits, where the odds ratios of MS in the lowest compared with the highest quartiles of exercise were 1.633 (95\% confidence interval [CI], 1.238-2.155) and $2.385(95 \%$ $\mathrm{Cl}, 1.771-3.212)$, respectively. Current smokers had 1.8-fold increased prevalence of MS compared to those who did not smoke at all. There were no significant associations with alcohol consumption.

\section{Odds Ratio of Osteopenia According to Fitness}

$\mathrm{VO}_{2 \max }$ had a strong inverse association with the risk of having osteopenia. Men in the third quartile of $\mathrm{VO}_{2 \max }(29.8$ $\mathrm{mL} / \mathrm{kg} / \mathrm{min})$ had 1.4 fold $(95 \% \mathrm{Cl}, 1.0-1.9 ; \mathrm{p}=0.048)$ greater likelihood of having osteopenia than those with a $\mathrm{VO}_{2 \max }$ in the highest quartile $(39.3 \mathrm{~mL} / \mathrm{kg} / \mathrm{min})$ after adjusting for age (Table 3). After adjusting for age, BMl, etc., the least fit men were almost 1.6 fold $(95 \% \mathrm{Cl}, 1.2-2.4 ; \mathrm{p}=0.003)$ more likely to have osteopenia than those with high $\mathrm{VO}_{2 \max }$. Grip strength had also an inverse association with osteopenia. Men with grip strengths of 40.4, 36.6, and $31.2 \mathrm{~kg}$ had 1.3-, 1.3-, and 1.4-fold increased likelihoods of having osteopenia, respectively. Furthermore, there was significant association at the lowest quartile (odds ratio, 1.4; 95\% Cl, 1.1-1.9; $p=0.004$ ) after adjusting for several variables. Flexibility was inversely associated with the risk of having osteopenia. Men in the fourth quartile $(-9.6 \mathrm{~cm})$ had 1.2 fold $(95 \% \mathrm{Cl}, 1.2-1.9 ; \mathrm{p}=0.003)$ greater likelihood of having osteopenia than those in the highest quartile of flexibility $(13.9 \mathrm{~cm})$.

\section{DISCUSSION}

This study assessed the association between grip strength, $\mathrm{VO}_{2 \max }$, power, flexibility, and bone health in a sample of mi-

Table 1. Subject characteristics

\begin{tabular}{|c|c|c|c|}
\hline Variable & Normal $(n=2,386)$ & Low bone mass $(n=1,174)$ & p-value \\
\hline Age (yr) & $49.9 \pm 5.0$ & $50.4 \pm 5.1$ & $0.002^{*, \dagger}$ \\
\hline Height $(\mathrm{cm})$ & $170.8 \pm 5.7$ & $169.2 \pm 5.6$ & $<0.001^{*}$ \\
\hline Weight $(\mathrm{kg})$ & $73.9 \pm 8.8$ & $69.2 \pm 8.7$ & $<0.001^{*}$ \\
\hline BMI $\left(\mathrm{kg} / \mathrm{m}^{2}\right)$ & $25.3 \pm 2.6$ & $24.1 \pm 2.7$ & $<0.001^{*, \dagger}$ \\
\hline Waist circumference $(\mathrm{cm})$ & $87.2 \pm 6.9$ & $84.8 \pm 7.3$ & $<0.001^{*, \dagger}$ \\
\hline Lumbar spine $1-4 \mathrm{BMD}\left(\mathrm{g} / \mathrm{cm}^{2}\right)$ & $1.191 \pm 0.15$ & $0.952 \pm 0.10$ & $<0.001^{*}$ \\
\hline Femoral neck BMD $\left(\mathrm{g} / \mathrm{cm}^{2}\right)$ & $0.958 \pm 0.13$ & $0.800 \pm 0.12$ & $<0.001^{*}$ \\
\hline Testosterone $(\mathrm{pg} / \mathrm{mL})$ & $5.9 \pm 2.9$ & $5.9 \pm 3.1$ & 0.625 \\
\hline Alkaline phosphate (mg/dL) & $61.5 \pm 15.8$ & $65.9 \pm 16.8$ & $<0.001 *$ \\
\hline Calcium (mg/dL) & $9.4 \pm 0.3$ & $9.4 \pm 0.4$ & $0.897^{\dagger}$ \\
\hline Phosphorus (mg/dL) & $3.8 \pm 0.7$ & $3.8 \pm 0.9$ & $0.002^{*, \dagger}$ \\
\hline $\mathrm{VO}_{2 \max }(\mathrm{mL} / \mathrm{kg} / \min )$ & $32.0 \pm 5.9$ & $31.4 \pm 5.6$ & $0.041^{*, \dagger}$ \\
\hline Grip strength $(\mathrm{kg})$ & $39.3 \pm 6.1$ & $37.6 \pm 5.8$ & $<0.001^{*, \dagger}$ \\
\hline Flexibility (cm) & $3.1 \pm 9.2$ & $2.0 \pm 9.1$ & $0.004^{*}$ \\
\hline $\mathrm{SBP}(\mathrm{mmHg})$ & $120.6 \pm 13.7$ & $120.1 \pm 14.2$ & 0.251 \\
\hline $\mathrm{DBP}(\mathrm{mmHg})$ & $76.1 \pm 9.1$ & $76.1 \pm 9.7$ & 0.999 \\
\hline Total cholesterol (mg/dL) & $194.2 \pm 33.8$ & $195.5 \pm 35.2$ & 0.279 \\
\hline Triglyceride (mg/dL) & $151.8 \pm 103.9$ & $147.8 \pm 94.0$ & 0.263 \\
\hline HDL-C (mg/dL) & $50.9 \pm 11.9$ & $52.3 \pm 12.8$ & $<0.001^{*}$ \\
\hline LDL-C (mg/dL) & $126.6 \pm 29.3$ & $127.0 \pm 29.8$ & 0.648 \\
\hline Fasting glucose $(\mathrm{mg} / \mathrm{dL})$ & $103.4 \pm 19.9$ & $101.2 \pm 17.0$ & $<0.001^{*}$ \\
\hline $\mathrm{HbA}_{1 \mathrm{c}}(\mathrm{mg} / \mathrm{dL})$ & $5.6 \pm 0.8$ & $5.5 \pm 0.8$ & $0.016^{*}$ \\
\hline
\end{tabular}

Values are presented as mean \pm standard deviation.

$\mathrm{BMI}$, body mass index; $\mathrm{BMD}$, bone mineral density; $\mathrm{VO}_{2 \max }$, maximum oxygen consumption; $\mathrm{SBP}$, systolic blood pressure; DBP, diastolic blood pressure; HDL-C, high-density lipoprotein cholesterol; LDL-C: low-density lipoprotein cholesterol; $\mathrm{HbA}_{1 \mathrm{c}}$, glycosylated hemoglobin. *p-values obtained by t-test. ${ }^{\dagger} \mathrm{p}$-values obtained by stepwise multiple regression analysis. 
ddle-aged Korean men. There are few studies on osteopenia related to physical fitness; therefore, the present study focused on this topic as well as flexibility. Osteopenia has a high incidence rate in women and elderly people, but this study included both middle-aged and elderly men. The American College of Sports Medicine ${ }^{1)}$ recommends that all adults should engage in strength exercises 2 days per week to prevent bone metabolic disease including osteopenia and osteoporosis. The National Osteoporosis Foundation guidelines also emphasize participation in not only weight-bearing activity but also weight-lifting, tai-chi, and dancing before an individual with decreased BMD engages in a vigorous exercise program such as running ${ }^{19)}$.

Our findings in part, agree with those of previous studies of similarly aged populations. Schwarz et al. ${ }^{11)}$ found that high hip BMD was significantly associated with higher cardiopulmonary fitness, and leg power $(p=0.0022$ and $p=0.011$, respectively), in men aged 31-60 years. We have shown that grip strength, $\mathrm{VO}_{2 \max }$ and flexibility were strongly associated with osteopenia and BMD in middle-aged men and that these relationships remain significant after adjusting for age and weight. Interestingly, power was not associated with measures of BMD and osteopenia in this cohort of middle-aged adults. In a study of 153 randomly sampled men, the age-ad-

Table 2. Health-related habits and rates of osteopenia

\begin{tabular}{|c|c|c|c|c|c|c|}
\hline Variable & Normal $(n=2,386)$ & Osteopenia $(\mathrm{n}=1,174)$ & p-value & OR & 95\% CI & p-value \\
\hline \multicolumn{7}{|l|}{ Exercise frequency } \\
\hline Every day & $12.3 \%$ & $8.4 \%$ & $<0.001^{*}$ & 1.000 & - & - \\
\hline 3-5 days/wk & $33.7 \%$ & $31.3 \%$ & & 1.473 & $1.114-1.947$ & $0.007^{*}$ \\
\hline 1-2 days/wk & $36.7 \%$ & $35.8 \%$ & & 1.633 & $1.238-2.155$ & $<0.001 *$ \\
\hline None & $17.3 \%$ & $24.5 \%$ & & 2.385 & $1.771-3.212$ & $<0.001 *$ \\
\hline \multicolumn{7}{|l|}{ Alcohol consumption } \\
\hline 0-1 days/wk & $36.0 \%$ & $39.0 \%$ & 0.309 & 1.000 & - & - \\
\hline 2-3 days/wk & $37.1 \%$ & $34.1 \%$ & & 0.880 & $0.738-1.049$ & 0.154 \\
\hline 4-6 days/wk & $18.7 \%$ & $18.9 \%$ & & 1.041 & $0.842-1.286$ & 0.713 \\
\hline Everyday & $8.2 \%$ & $8.0 \%$ & & 0.992 & $0.742-1.326$ & 0.955 \\
\hline \multicolumn{7}{|l|}{ Smoking history } \\
\hline None & $18.2 \%$ & $13.4 \%$ & $<0.001^{*}$ & 1.000 & - & - \\
\hline Past, now nonsmoker & $47.9 \%$ & $46.9 \%$ & & 1.447 & $1.153-1.815$ & $<0.001^{*}$ \\
\hline Current smoker & $33.8 \%$ & $39.6 \%$ & & 1.806 & $1.429-2.283$ & $<0.001^{*}$ \\
\hline
\end{tabular}

OR, odds ratio; CI, confidence interval.

*p-values obtained by logistic regression with adjustments for age, body mass index, waist circumference, phosphorus, testosterone, calcium, grip strength, maximum oxygen consumption, and other health habits.

Table 3. Odds ratios of osteopenia according to fitness level

\begin{tabular}{|c|c|c|c|c|c|c|c|c|}
\hline \multirow{2}{*}{ Variable } & \multirow{2}{*}{ Q } & \multirow{2}{*}{ Value (\%) } & \multicolumn{3}{|c|}{ Model 1} & \multicolumn{3}{|c|}{ Model 2} \\
\hline & & & OR & $95 \% \mathrm{CI}$ & p-value & OR & $95 \% \mathrm{CI}$ & p-value \\
\hline \multirow{4}{*}{$\begin{array}{l}\mathrm{VO}_{2 \max } \\
(\mathrm{mL} / \mathrm{kg} / \mathrm{min})\end{array}$} & 1 & 39.3 & 1.000 & - & - & 1.000 & - & - \\
\hline & 2 & 33.3 & 1.220 & $0.864-1.670$ & 0.298 & 1.423 & $1.012-1.967$ & $0.042^{\prime}$ \\
\hline & 3 & 29.8 & 1.383 & $1.055-1.986$ & 0.078 & 1.654 & $1.193-2.366$ & $0.002^{\prime}$ \\
\hline & 4 & 24.7 & 1.183 & 0.849-1.694 & 0.370 & 1.687 & $1.193-2.387$ & $0.003^{\prime}$ \\
\hline \multirow{4}{*}{$\begin{array}{l}\text { Grip strength } \\
(\mathrm{kg})\end{array}$} & 1 & 46.4 & 1.000 & - & - & 1.000 & - & - \\
\hline & 2 & 40.4 & 1.608 & $1.178-1.987$ & $<0.001^{*}$ & 1.264 & $0.987-1.648$ & 0.098 \\
\hline & 3 & 36.6 & 1.987 & $1.519-2.479$ & $<0.001^{*}$ & 1.276 & $0.997-1.654$ & $0.045^{\prime}$ \\
\hline & 4 & 31.2 & 1.992 & $1.538-2.569$ & $<0.001 *$ & 1.445 & $1.099-1.857$ & $0.004^{\prime}$ \\
\hline \multirow{4}{*}{$\begin{array}{l}\text { Flexibility } \\
(\mathrm{cm})\end{array}$} & 1 & 13.9 & 1.000 & - & - & 1.000 & - & - \\
\hline & 2 & 6.3 & 1.187 & $0.917-1.488$ & 0.234 & 1.255 & $0.978-1.560$ & 0.087 \\
\hline & 3 & 0.1 & 1.214 & $0.868-1.369$ & 0.445 & 1.324 & $0.889-1.467$ & 0.365 \\
\hline & 4 & -9.6 & 1.324 & $1.040-1.679$ & $0.020^{*}$ & 1.454 & $1.194-1.887$ & $0.003^{\prime}$ \\
\hline
\end{tabular}

Model 1, adjusted for age; model 2, adjusted for age, body mass index, waist circumference, phosphorus level, testosterone level, calcium level, grip strength, maximum oxygen consumption, exercise, smoking status, and alcohol consumption; Q, quartile; OR, odds ratio; $\mathrm{CI}$, confidence interval.

"p-values obtained by logistic regression; 
justed model association between $\mathrm{VO}_{2 \max }$ grip strength, leg power, and the likelihood of BMD decreased with increasing fitness ${ }^{111}$. In our study, low $\mathrm{VO}_{2 \max }$ and grip strength were associated with the presence of osteopenia. Low grip strength has usually been less strongly associated with the risk of bone metabolic diseases compared to higher strength ${ }^{20)}$. A number of studies of hand grip strength and BMD have been performed long ago, and the test was used to measure physiologic function in the elderly,20-22). The results of the present study, indicating a link between low grip strength and increased prevalence of osteopenia, might lead to changes in the decreasing BMD in middle-aged men. The strongest predictor of grip strength was osteopenia and BMD. Several studies have reported an association between grip strength and BMD in various ages and $\operatorname{sex}^{3,11,23,24)}$ similar to the findings of our study.

An important finding of the present study is that directly measured $\mathrm{VO}_{2 \max }$ had a strong and independently graded association with the risk of having osteopenia. The least fit men $\left(\mathrm{VO}_{2 \max }=24.7 \mathrm{~mL} / \mathrm{kg} / \mathrm{min}\right.$, that third quartile) were almost 1.7 fold more likely to have osteopenia than the fittest men $\left(\mathrm{VO}_{2 \max }=39.3 \mathrm{~mL} / \mathrm{kg} / \mathrm{min}\right.$, fourth quartile) after adjusting for age. Even after adjusting for age, BMl, and several other factors, the least fit men had a nearly 1.7 fold likelihood of having osteopenia. Our findings are similar to those of 2 recent studies suggesting that low cardiopulmonary fitness is a major determinant of decreased $B M D^{6,25}$. A previous study found a higher association between grip strength and mineralization abnormalities in a large cohort of men and women participating in the Heath 2006 study $^{3)}$. A number of studies have demonstrated the association between aerobic fitness and $\mathrm{BMD}^{11,25,26)}$ similar to the results of the present study. However, opposite results were reported by Kemper et al. ${ }^{27)}$ in young adults. Cardiopulmonary fitness was not significantly correlated with wrist BMD. In addition, Stewart et al. ${ }^{28)}$ reported that aerobic fitness was not correlated with BMD.

The present study observed a significant site-specific association between fitness and BMD at the femoral neck compared to that of the spine. Similar results were reported by Gouveia et al. ${ }^{24)}$, in which total hip BMD in elderly male subjects was more highly correlated compared to that of the spine.

The present study assessed the relationship between flexibility and BMD, firstly. We found a significant difference in flexibility between the normal and osteopenia groups $(p=0.004)$. Previous studies of young men have assessed the effect of strength training on the range of motion ${ }^{29}$. Also, a pilot study defined fitness in terms of BMD and found yoga to be an effective method to build BMD after menopause ${ }^{30)}$.

A previous study of female tennis players reported that high exercise frequency affected bone tissue ${ }^{311}$. Our data shows similar results; the association between total and at least one of day exercise per week and osteopenia disappeared after adjusting for age and weight (Table 2). McVeigh et al. ${ }^{32)}$ observed an inverse response relationship between less activity, filled in questionnaire self-reporting method, and the likelihood of mineralization in rheumatoid arthritis. The present data agree with previous findings that less physical activity, as well as low fitness, are related to bone metabolic disease including osteopenia and osteoporosis ${ }^{21,24)}$.

However, this study had several limitations. The cross-sectional design has inherent limitations in determining the causality of the observations. Grip strength was calculated as the average of the higher of the 2 values for each hand. This may not explain associations between dominant or nondominant hands and BMD, although the difference between dominant and nondominant hand is nearly the same and relatively consistent ${ }^{33)}$. Furthermore, there were limitations in the physical activity questionnaire as it was used self-reporting and did not include questions regarding exercise intensity, time, and type. Although osteopenia is more common in the elderly and in women, our study's participants included only middle-aged and elderly men. In addition, this study did not consider daily activity levels, including whether someone was sedentary or had high activity levels. Although flexibility did not have a significant effect on osteopenia in this study, previous studies have reported that flexibility exercises alone have positive effects on flexibility, body fat reduction, and muscle strength in the elderly ${ }^{34)}$.

In conclusion, we have shown that grip strength, $\mathrm{VO}_{2 \max }$ and flexibility, but not leg power, are associated with BMD and the odds ratios of osteopenia. Future studies are needed to determine whether fitness and daily activity levels are associated with BMD in middle-aged women and whether this relationship also exists in longitudinal outcomes according to the type of fitness and in the presence of severe conditions such as osteoporosis.

This study determined the prevalence of osteopenia according to various physical strengths in middle-aged and elderly men. The results showed that the prevalence of osteopenia was higher in cardiopulmonary fitness, grip strength, and flexibility. The group with the lowest cardiorespiratory endurance increased about 1.6 times, and the grip and flexibility increased 1.4 times.

Conflicts of Interest Disclosures: The researchers claim no conflicts of interest.

\section{REFERENCES}

1. Swain DP, Brawner CA. ACSM's resource manual for guidelines for exercise testing and prescription. Philadelphia (PA): Lippincott Williams \& Wilkins; 2012.

2. Barry VW, Baruth M, Beets MW, Durstine JL, Liu J, Blair SN. Fitness vs. fatness on all-cause mortality: a meta-analysis. Prog Cardiovasc Dis 2014;56:382-90.

3. Aadahl M, Beyer N, Linneberg A, Thuesen BH, Jørgensen T. 
Grip strength and lower limb extension power in 19-72-year-old Danish men and women: the Health2006 study. BMJ Open 2011;1:e00192.

4. Bevier WC, Wiswell RA, Pyka G, Kozak KC, Newhall KM, Marcus R. Relationship of body composition, muscle strength, and aerobic capacity to bone mineral density in older men and women. J Bone Miner Res 1989;4:421-32.

5. Miller LE, Pierson LM, Pierson ME, Kiebzak GM, Ramp WK, Herbert WG, et al. Age influences anthropometric and fitnessrelated predictors of bone mineral in men. Aging Male 2009;12: 47-53.

6. Liberato SC, Maple-Brown L, Bressan J. Association between bone mineralization, body composition, and cardiorespiratory fitness level in young Australian men. J Clin Densitom 2015;18: 187-91.

7. Greenspan SL, Myers ER, Maitland LA, Resnick NM, Hayes WC. Fall severity and bone mineral density as risk factors for hip fracture in ambulatory elderly. JAMA 1994;271:128-33.

8 Schuit SC, van der Klift M, Weel AE, de Laet CE, Burger H, Seeman E, et al. Fracture incidence and association with bone mineral density in elderly men and women: the Rotterdam Study. Bone 2004;34:195-202.

9. Romagnoli E, Carnevale V, Nofroni I, D’Erasmo E, Paglia F, De Geronimo S, et al. Quality of life in ambulatory postmenopausal women: the impact of reduced bone mineral density and subclinical vertebral fractures. Osteoporos Int 2004;15:975-80.

10. Pocock N, Eisman J, Gwinn T, Sambrook P, Kelly P, Freund J, et al. Muscle strength, physical fitness, and weight but not age predict femoral neck bone mass. J Bone Miner Res 1989;4: 441-8.

11. Schwarz P, Jørgensen N, Nielsen B, Laursen AS, Linneberg A, Aadahl M. Muscle strength, power and cardiorespiratory fitness are associated with bone mineral density in men aged 31-60 years. Scand J Public Health 2014;42:773-9.

12. Stieglitz J, Beheim BA, Trumble BC, Madimenos FC, Kaplan $\mathrm{H}$, Gurven M. Low mineral density of a weight-bearing bone among adult women in a high fertility population. Am J Phys Anthropol 2015;156:637-48.

13. Remes T, Väisänen SB, Mahonen A, Huuskonen J, Kröger H, Jurvelin JS, et al. Aerobic exercise and bone mineral density in middle-aged finnish men: a controlled randomized trial with reference to androgen receptor, aromatase, and estrogen receptor alpha gene polymorphisms. Bone 2003;32:412-20.

14. Marin RV, Pedrosa MA, Moreira-Pfrimer LD, Matsudo SM, Lazaretti-Castro M. Association between lean mass and handgrip strength with bone mineral density in physically active postmenopausal women. J Clin Densitom 2010;13:96-101.

15. Iida T, Ikeda H, Shiokawa M, Aoi S, Ishizaki F, Harada T, et al. Longitudinal study on physical fitness parameters influencing bone mineral density reduction in middle-aged and elderly women: bone mineral density in the lumbar spine, femoral neck, and femur. Hiroshima J Med Sci 2012;61:23-8.

16. Iwamoto J, Takeda T, Sato Y, Uzawa M. Effect of whole-body vibration exercise on lumbar bone mineral density, bone turnover, and chronic back pain in post-menopausal osteoporotic women treated with alendronate. Aging Clin Exp Res 2005;17: 157-63.

17. Totosy de Zepetnek JO, Giangregorio LM, Craven BC. Wholebody vibration as potential intervention for people with low bone mineral density and osteoporosis: a review. J Rehabil Res Dev 2009;46:529-42.

18. World Health Organization. Prevention and management of osteoporosis: report of a WHO scientific group. Geneva (Switzerland): World Health Organization; 2003.

19. Cosman F, de Beur SJ, LeBoff MS, Lewiecki EM, Tanner B, Randall S, et al. Clinician's guide to prevention and treatment of osteoporosis. Osteoporos Int 2014;25:2359-81.

20. Roberts HC, Denison HJ, Martin HJ, Patel HP, Syddall H, Cooper $\mathrm{C}$, et al. A review of the measurement of grip strength in clinical and epidemiological studies: towards a standardised approach. Age Ageing 2011;40:423-9.

21. Pocock NA, Eisman JA, Yeates MG, Sambrook PN, Eberl S. Physical fitness is a major determinant of femoral neck and lumbar spine bone mineral density. J Clin Invest 1986;78:618-21.

22. Hollingsworth JW, Hashizume A, Jablon S. Correlations between tests of aging in Hiroshima subjects--an attempt to define "physiologic age". Yale J Biol Med 1965;38:11-26.

23. Skelton DA, Greig CA, Davies JM, Young A. Strength, power and related functional ability of healthy people aged 65-89 years. Age Ageing 1994;23:371-7.

24. Gouveia ÉR, Maia JA, Beunen GP, Blimkie CJ, Rodrigues AL, Freitas DL. Functional fitness and bone mineral density in the elderly. Arch Osteoporos 2012;7:75-85.

25. El Hage R, Zakhem E, Theunynck D, Zunquin G, Bedran F, Sebaaly A, et al. Maximal oxygen consumption and bone mineral density in a group of young Lebanese adults. J Clin Densitom 2014;17:320-4.

26. Tucker LA, Nokes NR, Bailey BW, Lecheminant JD. Cardiorespiratory fitness and hip bone mineral density in women: a 6-year prospective study. Percept Mot Skills 2014;119:333-46.

27. Kemper HC, Twisk JW, van Mechelen W, Post GB, Roos JC, Lips P. A fifteen-year longitudinal study in young adults on the relation of physical activity and fitness with the development of the bone mass: The Amsterdam Growth and Health Longitudinal Study. Bone 2000;27:847-53.

28. Stewart KJ, Deregis JR, Turner KL, Bacher AC, Sung J, Hees PS, et al. Fitness, fatness and activity as predictors of bone mineral density in older persons. J Intern Med 2002;252:381-8.

29. Pinto RS, Gomes N, Radaelli R, Botton CE, Brown LE, Bottaro $\mathrm{M}$. Effect of range of motion on muscle strength and thickness. J Strength Cond Res 2012;26:2140-5.

30. Fishman LM. Yoga for osteoporosis: a pilot study. Top Geriatr Rehabil 2009;25:244-50.

31. Haapasalo H, Kannus P, Sievänen H, Pasanen M, Uusi-Rasi K, Heinonen A, et al. Effect of long-term unilateral activity on bone mineral density of female junior tennis players. J Bone Miner Res 1998;13:310-9.

32. McVeigh J, Straker L, Prioreschi A, Makda M, Tikly M. In people with rheumatoid arthritis, bone mineral density is lower in those more sedentary and less active. J Sci Med Sport 2014; 18:e14-5.

33. Bohannon RW. Grip strength: a summary of studies comparing dominant and nondominant limb measurements. Percept Mot Skills 2003;96(3 Pt 1):728-30.

34. Jin YS, Kim YK, Park EK, Choi HJ, Park JY. The effects longterm stretching exercise on health related fitness of the elderly women. J Korean Geriatr Soc 1999;3:28-36. 